court does not have the advantage of seeing the witnesses, so that it will be reluctant to disturb a finding of an inferior tribunal that one witness is more credible than another. But the appeal court will be willing to say in appropriate cases that there was no evidence to support a particular finding of fact, or that the primary facts found do not support the inferences of fact drawn from them.

When appealing from a reasoned judgment of, say, a High Court judge, the above principles have a logical and clear foundation. But the G.M.C. gives no reasons for its decisions, and so the Privy Council has to take a comprehensive view of all the evidence as it appears in the record, and try to determine whether a proper inquiry was made and a proper finding was made on it. Errors of procedure and the wrong admission of evidence are too common in judicial processes in general for such an event to entitle an appellant automatically to acquittal. Consequently if an error occurs in the G.M.C.'s deliberations the Privy Council has to determine whether without the error and its results there would still have been enough evidence to justify the G.M.C.'s finding.

It is notable that there is only one civil or criminal court of the land where there is neither a summing-up nor a reasoned judgment-namely, the Petty Sessional Magistrates' Court. From this court an appeal may be made to Quarter Sessions, which is in fact a rehearing in the sense that witnesses are called and examined and cross-examined afresh. This form of appeal, however, has its disadvantages, and it would probably not be appropriate before the Privy Council. Appeals to the Privy Council from the G.M.C. might, on the other hand, be more satisfactory if the Disciplinary Committee gave reasons for its decision.

But not all appeals concern matters of fact, procedure, or evidence. Sometimes a doctor may wish to argue that a set of facts proved against him do not constitute infamous conduct in a professional respect. The Privy Council is, very properly, reluctant to vary by its decisions the code of conduct by which the medical profession governs itself, ${ }^{2}{ }^{3}$ though it might in an extreme case determine that the facts found were incapable of being described as infamous conduct. Although professional ethics are a matter of public concern, it is generally accepted that the professional bodies have a better appreciation of the problems than have laymen. There is perhaps a danger that a disciplinary committee might become overscrupulous in maintaining the niceties of the professional code, or it might fail to appreciate the need for adaptation to changed conditions. If either of these possibilities were to occur in the medical profession the Privy Council could possibly meet the situation by changing the rules of procedure so that senior medical men might sit with its Judicial Committee. In Admiralty matters the Judicial Committee may have two Admiralty assessors sitting with it. ${ }^{4}$

Disquiet is sometimes felt about appeals against the sentence that the G.M.C. imposes. It is worth noting therefore that the Privy Council is most reluctant to interfere in matters of sentence ${ }^{2}$ - some would argue too reluctant. But there would be fewer appeals against sentence if the G.M.C. had power to impose some punishment other than erasure. There is no reason in principle why the G.M.C. should not be given the power to order suspension from practice for a period, or perhaps censure. A grave offence committed in

\footnotetext{
1 Fox v. General Medical Council [1960] 1 WLR 1017

2 McCoan v. General Medical Council [1964] I WLR 1107

3 Brit. med. F., 1964, 2, 700.

- Judicial Committee Rules, 1957. S.I. No. 2224.
}

mitigating circumstances may require a more severe penalty than the "probation" imposed by postponing sentence yet one not so severe as erasure with no possibility of returning to the Register for at least a year. The Privy Council would be unlikely to interfere with the length of any suspension imposed, but it might decide that the G.M.C. had in certain cases erred in principle in ordering erasure when suspension was more appropriate, or vice versa.

\section{Identification of Tablets}

The number of different tablets, pills, and capsules used in medicine is already huge and is continually growing. Both in general practice and in hospitals much time may be necessary to identify unnamed tablets, and in cases of poisoning this may lead to serious delay in starting treatment.

Though the Standing Pharmaceutical Advisory Committee stated that "it has always been considered to be bad pharmaceutical practice to rely on colour or surface markings for the identification of tablets," there is widespread support for the introduction of a scheme of identification but divergent views on its practicability. The Report of the Subcommittee on Emergency Treatment of Poisoning in Hospitals recommended the appointment of a committee to consider the subject, but in a footnote included this opinion of the Standing Pharmaceutical Advisory Committee. ${ }^{1}$ R. Goulding, director of the National Poisons Information Centre set up as a result of the report, recently recommended the compilation of a central index which would enable doctors to obtain immediately, day and night, information for the identification of poisonous substances. ${ }^{2}$ Meanwhile representatives of the British Medical Association, the Association of British Pharmaceutical Industry, and the Pharmaceutical Society of Great Britain met on 8 December 1964 to consider proposals for the identification of tablets. It was agreed that an investigation be made into the possibility of finding a workable method. The views of the Pharmaceutical Society may perhaps be inferred from a leading article in the Pharmaceutical fournal of 13 February. It comes out against the marking of tablets by code numbers and favours identification, through a central index, by physical characteristics such as size, shape, colour, and others.

Many firms have made identification schemes for their own products-by colours, marks, letters, and numbers. The use of colours for identification ${ }^{3}$ has many disadvantages, not the least being that there are not enough distinctive colours or combinations of colours to produce a comprehensive and unambiguous system. J. W. D. Whitney ${ }^{4}$ has suggested a scheme in which each product would be identified by a diestamped number and the firm's name or initials. He proposed that B.P. and B.P.C. tablets should be similarly marked. J. J. H. Hastings ${ }^{5}$ discussed from the point of view of a pharmaceutical manufacturer some of the problems that would arise in providing a scheme of this type and concluded that, though not easy to carry out, it is technically feasible. The joint committee of the British Medical Association and the Pharmaceutical Society ${ }^{6}$ also thought that Whitney's scheme is feasible but that it would be prohibitively expensive. Costs of production would be greatly increased by the necessity for firms to purchase and maintain many new sets of tablet punches and special expensive apparatus for marking coated tablets and capsules. Provision would also have to be made 
for the marking of imported tablets. On the evidence available the committee believed that to mark all tablets would increase the National Health Service drug bill by several million pounds a year. Higher manufacturing costs would also affect the ability of the pharmaceutical industry to compete in overseas markets. Consequently in 1961 the Committee on Medical Science, Education, and Research of the British Medical Association ${ }^{7}$ reported to the B.M.A. Council that, however desirable, a scheme of tablet identification is impracticable. The Minister of Health's Standing Pharmaceutical Advisory Committee reached the same conclusion.

But the need remained, and ideas continued to flow. W. A. L. Collier ${ }^{8}$ suggested in 1962 the coded imprinting of tablets to give their general therapeutic classification, year of production, dosage, manufacturer, and other details. Another approach is the production of guides for the identification of tablets and capsules by means of their existing colours, markings, or shapes. Thus in 1956 the Chemist and Druggist ${ }^{9}$ published a Tablet and Capsule Identification Guide. It comprised charts showing the distinctive markings of white tablets, apart from those actually bearing the name of the tablet or with the same markings used for several different tablets (e.g., the Tabloid series). It also gave charts showing the distinctive hues, sizes, and shapes of coloured tablets and capsules. This was later issued as a booklet and as a set of cards. Revised versions were published in 1961 and a further edition is in the press. Recently a firm of tablet manufacturers introduced a series of coded tablets under the trade name of Co-Tabs. According to a circular letter from the Ministry of Health (C/D 137/14): " The net ingredient cost of Co-Tabs, based on the 250 pack and related to the frequency of ordering of the standard official tablets, exceeds by about $10 \%$ the present Drug Tariff payment for the official drugs." The Ministry adds that it has requested the Association of the British Pharmaceutical Industry to try to ensure that, if other manufacturers decide to make coded tablets, a common identification code is used.

Punched cards offer a means of rapid identification of tablets, and C. McArdle and E. A. Skew ${ }^{10}$ have suggested a scheme. The cards record the physical characteristics of known tablets-size, colour, shape, markings, and coating. When it is necessary to identify an unknown tablet punch holes are made on a blank card, and this is then compared with the prepared cards and finally with a sample of the tablet indicated by the standard card. This scheme has been patented and the cards can be purchased. The American Medical Association ${ }^{11}$ has published an identification guide based on a scheme devised by J. J. Hefferren. ${ }^{12}$ In this code numbers are assigned to more than 5,000 preparations. The guide also uses physical characteristics including specific

\footnotetext{
${ }^{1}$ Bmergency Treatment in Hospitals of Cases of Acute Poisoning. 1962. H.M.S.O., London.

The Times, 30 December 1964, p. 4.

Pharm. F., 1957, 178, 71.

- Whitney, J. D. W., Brit. med. F., 1960, 1, 50.

Hastings, J. J. H., Pharm. J., 1960, 184, 45.

- Ibid., 1961, 186, 414.

7 Brit. med. f. Suppl., 1961, 2, 167.

${ }^{8}$ Collier, W. A. L., Lancet, 1962, 1, 473

- Chemist and Druggist, 1956, 165, 602.

${ }^{10}$ McArdle, C., and Skew, E. A., Lancet, 1961, 2, 924

1 F. Amer. med. Ass., 1962, 182, 1145.

1 Hefferren, J. J., ibid., 1959, 169, 479.

soldwell, J. G., Shoman, A. F., Hurst, C. B., and Robertson, W. O., bid., 1964, 187, 951 .

14 Collier, W. A. L., Pharm. F., 1964, 192, 169.

15 An Index (or Dictionary) of Imprints Used on Tablets and Other Solid Dosage Forms. Donald Ferrier Ltd., Edinburgh, 1964. 5s. net.

18 Pharm. F., 1964, 193, 485.

1 Cronhelm, H. J., Brit. med. F., 1965, 1, 129

18 Summers, F. H., Pharm. F., 1965, 194. 3.
}

dimensions, reference colours, and imprints. J. G. Caldwell and colleagues ${ }^{13}$ made a series of studies of this guide and found that, though it was useful in identifying many preparations, errors amount to $44 \%$. They recommended adoption of a system of imprinting additional coded information on all solid-dosage preparations as suggested by Whitney ${ }^{4}$ and Collier. ${ }^{8}$

Last year Collier ${ }^{14}$ published An Index of Imprints on Solid Dosage Forms in Britain and the U.S.A., and this has now appeared as a booklet. ${ }^{15}$ It classifies the markings on tablets and other solid-dosage preparations according to the presence or absence of scoring and the presence of numbers or letters or both. Though at first sight the index seems complicated, it is easily mastered and can be used for the certain identification of a large number of tablets and capsules.

The General Practice Subcommittee of the Pharmaceutical Society ${ }^{16}$ has expressed concern lest the introduction of coded tablets should lead to prescription by code letters and encourage "reading the tablet" instead of reading the label.

It would be relatively easy to devise an index of letters and numbers to be put on the labels of containers for all soliddosage preparations as suggested recently in our correspondence columns. ${ }^{17}$ Such an index number could be included in all official publications such as the B.P., B.P.C., and B.N.F. A scheme of this type has been devised for B.N.F. tablets and capsules by Summers. ${ }^{18}$ For an index of this type to achieve maximum usefulness international agreement would be needed, and possibly legislation, to compel all products sold or dispensed to be labelled with the index number. Such an index would be very much cheaper than any scheme for the imprinting of all tablets. It would, however, suffer from the serious disadvantage that patients might transfer tablets from one container to another.

The outcome of the present investigations will be awaited with great interest.

\section{Alcohol in the Driver}

The recommendation from its Alcohol and Road Accidents Committee which the Council of the B.M.A. approved last week reads as follows (see Supplement, p. 61):

"That the Government be asked to introduce legislation making it an offence for a person with a blood-alcohol concentration in excess of $80 \mathrm{mg} . / 100 \mathrm{ml}$. to drive a motor vehicle on the public highway."

Though similar legislation exists in other countries it would be new to Great Britain. Perhaps it is this novelty which is responsible for some of the misconceptions about the proposal that have found expression in the press. The concentration of $80 \mathrm{mg}$. per $100 \mathrm{ml}$. in the blood is not a "safe" limit of any kind. To attain it in ordinary social drinking over an evening, for instance, would entail the drinking of something like 5-12 single whiskies or $4 \frac{1}{2}$ to 6 pints of beer-and these are very rough approximations. There is in fact only one

\footnotetext{
Relation of Alcohol to Road Accidents. British Medical Association. 1960.

2 Brit. med. F., 1964, 2, 1546.

s Borkenstein, R. F., el al., The Role of the Drinking Driver in Traffic Accidents, ed. Allen Dale. Department of Police Administration, Indiana University. 1964.

- Haisman, M. F., Kimber, K. J., and Walls, H. J., Brit. F. Addict., 1963, 59, 25.
} 